\title{
PENGARUH RELIGIUSITAS DAN SKALA KECERDASAN BUDAYA TERHADAP ETHNOSENTRISME KONSUMEN BAGI PRODUK ASING 2019
}

\author{
Hatimy Paulin Doerleben \\ Made Siti Sundari \\ Fakultas Bisnis dan Ekonomika, Universitas Surabaya \\ Email: hdoerleben72@gmail.com
}

\begin{abstract}
This study seeks to understand the complicated relationship between religiosity and ethnocentrism of consumers by examining the mediating variable of cultural intelligence. The empirical model involves a structural equation model (SEM) with a data collection of 684 internet-user respondents. The results show that there was a positive impact of religiosity on consumer Ethnocentrism. In addition, the results also indicate that cultural intelligence strengthens the relationship between religiosity and ethnocentric consumerism. Overall, this study extends the discussion on cultural identity that incorporate into Ricardian model of international trade.

Keyword: Consumer Ethnocentrism, Religiosity, Cultural Intelligence Scale
\end{abstract}

\section{PENDAHULUAN}

Pada era global dan modern, tidak sedikit masyarakat telah melupakan budaya asal karena budaya asing mudah masuk ke Indonesia. Melalui produk barang maupun jasa yang ditawarkan dari luar negri akan melunturkan kekuatan budaya lokal.

Seiring dengan lunturnya budaya Indonesia, masyarakat mulai tertarik dan berlomba- lomba membeli produk asing yang tidak hanya kualitas yang telah terpercaya namun juga karena tingkat prestige yang diberikan oleh produk asing tersebut. Hal ini tentu sangat memprihatinkan, karena seharusnya masyarakat Indonesia menjadi pelopor majunyamerek lokal di kancah internasional akan tetapi yang terjadi justru bangga mengkonsumsimerek asing daripada merek lokal.

Kemudahan produk asing memasuki pasar merupakan hal yang perlu di perhatikan lebih lanjut, mengingat produk tersebut akan bersaing dengan produk lokal Indonesia. China merupakan negara asal impor terbesar karena sebagian besar barang di Indonesia terdapat label "made in China".

Berdasarkan data Badan Pusat Statistika (2016), nilai impor Indonesia dari China mencapai US\$ 7,13 miliar. Hal ini dapat dilihat di Tabel 1 yang menunjukkan banyaknyaproduk China yang masuk ke Indonesia yang bernilai sampai milyar US\$

Produk China yang masuk ke Indonesia memiliki keunggulan dari segi harga dibandingkan dengan produk lokal, oleh karena itu masyarakat Indonesia lebih senang mengkonsumsi produk asing daripada produk lokal. Seiring dengan berkembangnya zaman dan terus diperbaharuinya setiap aturan dengan berbagai kemudahan bagi produk impor, maka akan besar kemungkinan produk lokal kalah bersaing dengan produk asing di pasar Indonesia.

Individu yang memutuskan untuk memilih produk dan merek dalam negeri maupun luar negeri membuktikan bahwa keputusan yang diambil tersebut merupakan latar belakang dari adanya faktor Ethnosentrisme (Shimp and Sharma, 
1987, Watson \& Wright, 2000, Yoo \& Donthu, 2005). Sikap Ethnosentrisme cenderung memilih untuk membeli produk dalam negeri daripada produk asing, karena individu akan berfikir bahwa membeli produk asing akan merugikan perekonomian negara serta mengurangi lapangan kerja yangakibatnya pengangguran akan semakin tinggi.

\begin{tabular}{clc} 
Tabel 1 Produk Impor China Yang Masuk Ke Pasar Indonesia & (dalam US\$) \\
\hline No & \multicolumn{1}{c}{ Produk Impor } & Nilai Impor \\
\hline 1 & Mesin-mesin/pesawat mekanik & 1,76 miliar \\
2 & Mesin/peralatan listrik & 1,42 miliar \\
3 & Besi dan baja & 470,75 juta \\
4 & Bahan kimia organik & 276,69 juta \\
5 & Plastic dan barang dari plastik & 257,13 juta \\
6 & Benda-benda dari besi dan baja & 202,98 juta \\
7 & Filament buatan & 168,88 juta \\
8 & Pupuk & 146,09 juta \\
9 & Bahan kimia anorganik & 140,43 juta \\
10 & Kendaraan dan bagiannya & 134,53 juta \\
11 & Lainnya & 2,15 miliar \\
\hline
\end{tabular}

Sumber: Badan Pusat Statistika, 2016

Model perdagangan bebas Ricardian melihat Pareto selalu meningkat relatif terhadap negara-negara penganut autarki dengan asumsi persaingan sempurna, skala hasil konstan, dan tambahan faktor pendukung yang identik (Janeba, 2004). Ketika mengkonsumsiproduk asing, konsumen dipengaruhi oleh banyak faktor baik internal maupun eksternal. Faktor internal berasal dari diri individu itu sendiri, ketika individu merasa tertekan akan suatu hal baik itu pekerjaan atau masalah lainnya, maka individu akan cenderung untuk melampiaskan dengan belanja barang atau jasa, walaupun individu menyadari bahwa barang dan jasa tersebut tidak dibutuhkannya.

Fenomena tersebut merupakan bentuk penghargaan yang diberikan individu bagi dirinya sendiri guna menunjukkan hasil kerja atau kemampuan individu dalam memperoleh barang dan jasa tersebut. Tidak hanya individu sendiri yang menjadi salah satu faktor internal, religiusitas individu juga menjadi salah satu alasan individu dalam mengkonsumsi. Agama menjadi tolok ukur individu dalam memutuskan sesuatu serta membantu individu dalam memilah hal baik dan buruk yang terjadi disekitarnya (Pratono,2019).

Selain faktor internal, terdapat faktor eksternal yang juga mempengaruhi individu dalam melakukan pembelian seperti budaya asing yang mau tidak mau harus dipelajari oleh individu akibat tuntutan lingkungan individu yang mendorong individu untuk mempelajari budaya asing agar lebih cerdas dan mampu beradaptasi dengan lingkungan disekitarnya (Pratono \& Arli, 2020).

Setiap faktor-faktor yang mempengaruhi individu untuk membeli produk asing tentunya akan membawa dampak buruk baik bagi produk lokal maupun bagi negara itu sendiri. Melihat hal tersebut, maka permasalahan yang akan dibahas dalam penelitian ini adalah: Apakah faktor Skala Kecerdasan Budaya dan Religiusitas mempengaruhi Ethnosentrisme Konsumen bagi produk asing, serta apakah faktor Religiusitas mempengaruhi Skala Kecerdasan Budaya bagi produk asing? 


\section{METODE PENELITIAN}

Jenis penelitian yang dilakukan tergolong penelitian kuantitatif data-data pada penelitian ini dikumpulkan kemudian diolah dan dianalisis. Menurut Sugiyono (2015) data kuantitatif adalah data yang berbentuk angka atau data yang diangkakan (scoring). Data kuantitatif merupakan data yang cenderung dapat dianalisis dengan teknik statistic. Sumberdata yang digunakan dalam penelitian ini adalah data primer yang diperoleh dari pengumpulan data melalui penyebaran kuisioner kepada pengguna internet.

Aras pengukuran yang digunakan untuk semua variabel, baik dependen dan independen dalam penelitian ini adalah aras interval. Menurut (Zikmund, et.al., 2003) arasinterval merupakan aras pengukuran yang menunjukkan jarak yang sama dan selisih yangjelas pada skala. Skala pengukuran yang digunakan dalam penelitian ini adalah menggunakan skala likert, skala yang digunakan mulai dari interval 1-5 atau dimulai dari sangat setuju sampai sangat tidak setuju (Sangadji, $d k k$., 2010). Penelitian ini menggunakanskala likert sebagai berikut : a) STS: Sangat Tidak Setuju, b) TS: Tidak Setuju, c) N: Netral, d) S: Setuju dan e) SS: Sangat Setuju

Populasi yang menjadi fokus penelitian ini merupakan pengguna internet. Populasi adalah keseluruhan dari subjek penelitian dimana yang dimaksud adalah seluruh individu yang akan dijadikan sebagai obyek penelitian atau individu yang memiliki sifat yang samawalaupun prosentase kesamaan itu sedikit (Arikunto, 2013). Sampel adalah bagian dari jumlah dan karakteristik yang dimiliki oleh populasi tersebut. Sampel merupakan bagian dari populasi yang ada, sehingga dalam mengambil sampel dari populasi diperlukan cara tertentu yang didasarkan pada pertimbangan-pertimbangan yang ada. (Sugiyono, 2017) Data dikumpulkan dengan melalui:

1. Kuisioner, yaitu teknik pengumpulan data yang dilakukan dengan cara menyebar daftarpertanyaan kepada responden secara online untuk memperoleh jawaban atas pertanyaan-pertanyaan yang disediakan.

2. Peneltian kepustakaan, yaitu teknik pengumpulan data dengan cara peninjauan pustaka dari buku-buku, karya ilmiah yang menyangkut teori-teori yang berkaitan dengan masalah yang akan dibahas dari penelitian ini.

Berdasarkan data yang diperoleh peneliti pada 2019 dengan menggunakan tiga variabel antara lain Ethnosentrisme Konsumen, Religiusitas dan Skala Kecerdasan Budaya, maka model penelitian untuk ketiga variabel ditampilkan di Gambar 1.

Variabel dalam penelitian ini terdiri dari variabel dependen $(\mathrm{Y})$ dan variabel independen (X). Menurut Sugiyono (2017) variabel dependen adalah variabel terikat yaitu variabel yang dipengaruh. Sebagai variabel dependen (Y) adalah:

1. Ethnosentrisme Konsumen / Consumer Ethnocentrism ( $\left.\mathrm{Y}_{1}\right)$ : merupakan kecenderungan kelompok masyarakat/konsumen tertentu dalam hal menutup diri dari kelompok lainnya serta sulit menerima segala sesuatu yang bukan berasal dari kelompok mereka sendiri (Booth, 1979)

2. Skala Kecerdasan Budaya / Cultural Intelligence Scale (Y2): merupakan kemampuan individu beradaptasi dalam keragaman budaya baik dengan cara memahami, bertingkah laku hingga bagaimana ketepatan individu dalam berinteraksi denganindividu lain yang berasal dari budaya berbeda. 


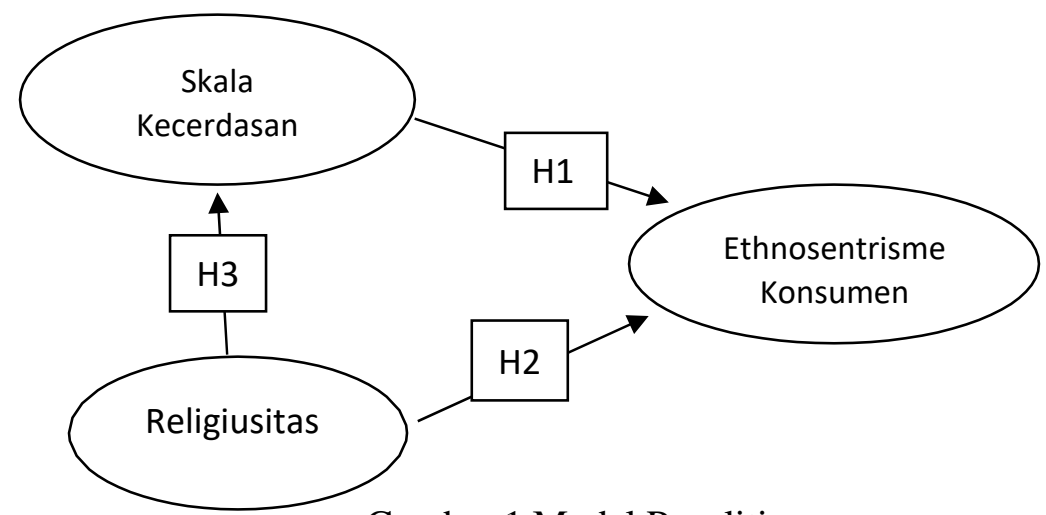

Gambar 1 Model Penelitian

Adapun Variabel independen (X) adalah variabel bebas. Variabel bebas adalah variabelyang mempengaruhi terjadinya perubahan terhadap variabel dependen atau yang biasa disebutvariabel terikat (Sugiyono, 2015). Adapun variabel yang digunakan sebagai variabel independen penelitian ini adalah pertama, Religiusitas / Religiousness (X1): motif yang menjadi dasar berbagai ekspresi dari keragaman yang dilakukan setiap individu (Allport \& Ross, 1967). Kedua, Skala Kecerdasan Budaya / Cultural Intelligence Scale (X2): kemampuanindividu untuk berguna dan mengelola secara efektif situasi keragaman budaya, yang memiliki hubungan dengan individu dalam kelompok, organisasi dan bahkan bangsa (Ang \& Van Dyne, 2015). Variabel dan Indikator yang digunakan dalam kuisioner dapat dilihat di Tabel 2.

Tabel 2: Variabel dan Indikator Penelitian

\begin{tabular}{|c|c|c|}
\hline Variabel & Indikator & Pertanyaan \\
\hline $\mathrm{s}$ & $\begin{array}{l}\text { 1. Individu harus membeli produk } \\
\text { dalam negeri. } \\
\text { 2. Mengurangi pembelian produk asing } \\
\text { demi perekonomian negara. }\end{array}$ & $\begin{array}{l}\text { 1. Orang Indonesia seharusnya } \\
\text { membeli barang buatan Indonesia. } \\
\text { 2. Kita seharusnya membeli barang } \\
\text { produk Indonesia, bukan } \\
\text { membiarkan negara lain menjadi } \\
\text { kaya karena menjual barangnya } \\
\text { kesini. }\end{array}$ \\
\hline Religiusitas & $\begin{array}{l}\text { 1. Individu mendalami Kitab Suci } \\
\text { agama masing-masing. } \\
\text { 2. Menerapkan setiap ajaran agama } \\
\text { dalam kehidupan sehari-hari. }\end{array}$ & $\begin{array}{l}\text { 1. Saya menikmati membaca Kitab Suci. } \\
\text { 2. Saya berusaha keras untuk hidup } \\
\text { sesuai dengan ajaran agama saya }\end{array}$ \\
\hline $\begin{array}{l}\text { Skala } \\
\text { Kecerdasan } \\
\text { Budaya }\end{array}$ & $\begin{array}{l}\text { 1. Individu menggunakan } \\
\text { pengetahuannya dalam berinteraksi } \\
\text { dengan budaya } \\
\text { 2. Individu mudah beradaptasi dengan } \\
\text { budaya baru. } \\
\text { 3. Individu memastikan bahwa } \\
\text { engetahuan yang dimilikinya cukup } \\
\text { luas sebelum berinteraksi dengan } \\
\text { budaya lainnya. }\end{array}$ & $\begin{array}{l}\text { 1. Saya secara sadar menggunakan } \\
\text { pengetahuan budaya ketika } \\
\text { berinteraksi dengan orang lain dari } \\
\text { budaya yang berbeda. } \\
\text { 2. Saya mampu menyesuaikan diri } \\
\text { ketika berinteraksi dengan orang dari } \\
\text { budaya yang tidak saya kenal. }\end{array}$ \\
\hline
\end{tabular}

Sumber: Allport \& Ross (1967); Shimp \& Sharma (1987); Thomas, et al., (2015)

Penelitian ini dalam menganalisis data primer yang diperoleh menggunakan Smart Partial Least Square (SmartPLS). SmartPLS merupakan metode alternatif dari SEM (Structural Equation Modeling) yang dapat digunakan untuk mengatasi permasalahan antara variabel yang kompleks namun dengan ukuran sampel data minimal 100 
(Hair, et.al., 2010). Peneliti menganalis data yang diperoleh dari hasil dari olahan data tersebut dengan menggunakan metode SEM.

Analisa menggunakan PLS dilakukan dengan 2 tahap yaitu pertama, Evaluasi Model Pengukuran (Outer Model): Evaluasi outer model merupakan model pengukuran untuk menilai validitas dan reliabilitas suatu model. Kedua, Evaluasi Model Struktural (Inner Model): Mengevaluasi inner model menggunakan R2 untuk variabel dependen, nilai koefisien path atau t-values tiap path untuk menguji signifikansi antar konstruk dalam model struktural.

\section{HASIL \& PEMBAHASAN}

Kuesioner berupa Google Form disebar secara online kepada pengguna internet melalui media sosial agar mempermudah responden untuk membuka dimanapun dan kapanpun. Terdapat 684 data yang telah melalui tahap penyaringan, responden terdiri dari berbagai jenjang karir dari mahasiswa hingga pekerja. Responden juga berasal dari berbagai daerah atau kota yang ada di Indonesia dan berbagai keyakinan yang dianut seperti: Islam, Kristen, Hindu, Budha serta Konghucu. Responden yang dipilih dengan kriteria tersebut guna menunjang penelitian yang dilakukan peneliti.

Data primer yang telah didapatkan oleh peneliti, diolah menggunakan Smart Partial Least Square (Smart PLS) dengan metode SEM. Hasil pengolahan data menunjukkan bahwa hubungan antara Religiusitas dan Ethnosentrisme Konsumen sebesar 0,199 atau 19,9\% sedangkan hubungan antara Religiusitas dan Skala Kecerdasan Budaya adalah 26,1\%.

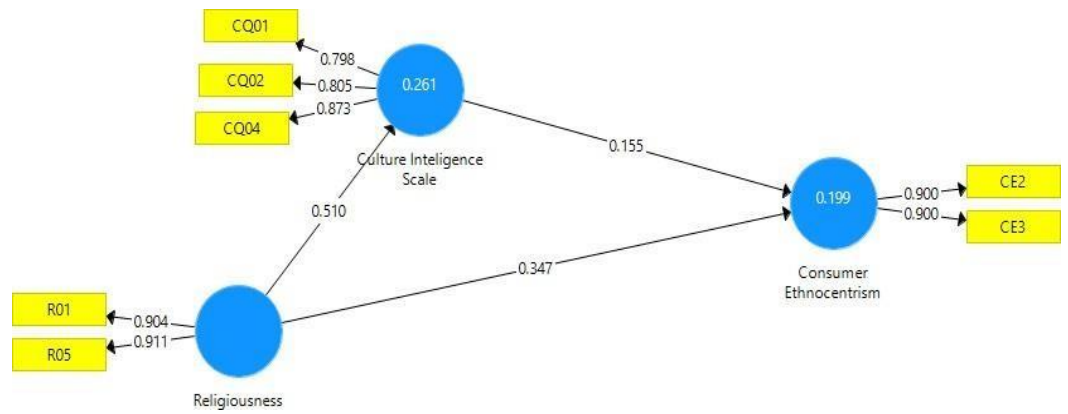

Gambar 2: Hasil Pengolahan Data

Gambar 2 menunjukkan bahwa Cronbach's Alpha setiap variabel lebih besar dari 0,7 yang artinya variabel dapat diterima dalam penelitian. Tingkat keandalan yang tinggi dapat ditunjukkan melalui uji Composite Reliability (CR), hasil uji Composite Reliability (CR) dianggap memuaskan dengan nilai lebih dari 0,865 karena telah diatas 0,70 . Oleh karena itu, dapat dikatakan bahwa data Ethnosentrisme Konsumen (CE), Skala Kecerdasan Budaya (CQ) dan Religiusitas (R) dapat dipercaya dan diandalkan serta dapatdipergunakan untuk uji hipotesis. Pengujian AVE memiliki nilai lebih besar dari 0,5 yangartinya bahwa variabel menjelaskan lebih dari setengah varians dari indikator sehingga menunjukkan tingkat komunalitas yang diterima. Melalui hasil tersebut maka semuaindikator sudah valid serta menunjukkan adanya keterkaitan yang baik antara indikator dengan konstruknya. Hal ini dapat dilihat pada Tabel 3. 
Tabel 3 Uji Reliabilitas dan Validitas

\begin{tabular}{lllll}
\hline & $\begin{array}{l}\text { Cronbach's } \\
\text { Alpha }\end{array}$ & rho_A & $\begin{array}{l}\text { Composite } \\
\text { Reliability }\end{array}$ & AVE \\
\hline Ethnosentrisme Konsumen (CE) & 0.766 & 0.766 & 0.895 & 0.810 \\
Skala Kecerdasan Budaya (CQ) & 0.772 & 0.811 & 0.865 & 0.682 \\
Religiusitas (R) & 0.787 & 0.787 & 0.904 & 0.824 \\
\hline
\end{tabular}

Sumber: Allport \& Ross (1967); Shimp \& Sharma (1987); Thomas, et al., (2015)

Pengujian Model Struktural (Inner Model) bertujuan untuk mengetahui hubungan antar konstruk, nilai siginifikasi dan $R$-square dari model penelitian. Hasil menunjukan bahwa nilai $R$-square untuk variabel Ethnosentrisme Konsumen sebesar 0.199, artinya bahwa 19,9\% variabel Ethnosentrisme Konsumen dipengaruhi oleh variabel Religiusitas. Sedangkan 26,1\% variabel Skala Kecerdasan Budaya dipengaruhi oleh variabelReligiusitas (Tabel 4).

Tabel 4 Nilai $R$-square

\begin{tabular}{ll}
\hline & $R$-square \\
\hline Ethnosentrisme Konsumen (CE) & 0.199 \\
Skala Kecerdasan Budaya (CQ) & 0.261 \\
\hline
\end{tabular}

Bootstrap merupakan analisis yang menunjukkan hubungan antar variabel dengan tanda koefisien regresi dan juga menggambarkan dampak dari indikator lainnya. Koefisien yang bernilai positif ditunjukkan oleh original sample, untuk tingkat signifikan pada penelitian ini, nilainya lebih besar dari 3,49 yang artinya signifikan karena lebih tinggi dari 1,96. Apabila ingin mengetahui nilai probabilitas kesalahan dapat dilihat melalui p-values, dalam penelitian ini semua variabel memiliki nilai probabilitas kurang 5\%, maka dari semua hasil penelitian bootstrap tersebut semua hipotesis dapat diterima karena telah memenuhi nilai-nilai minimum yang telah ditentukan

Tabel 5 Path Coefficients Variabel-Variabel Penelitian

\begin{tabular}{|c|c|c|c|c|c|}
\hline \multicolumn{2}{|c|}{$\underset{\rightarrow}{\operatorname{Original} \text { Sample }}$} & $\begin{array}{l}\text { Sample } \\
\text { Mean }\end{array}$ & $\begin{array}{l}\text { Standard } \\
\text { Dev }\end{array}$ & t Statictics & $P$ Values \\
\hline $\mathrm{CE}$ & 0.155 & 0.157 & 0.044 & 3.496 & 0.001 \\
\hline $\mathrm{R} \longrightarrow \mathrm{CE}$ & 0.347 & 3.44 & 0.042 & 8.223 & 0.000 \\
\hline $\mathrm{R} \rightarrow \mathrm{CQ}$ & 0.51 & 0.512 & 0.032 & 15.887 & 0.000 \\
\hline
\end{tabular}

Hasil original sample di Tabel 5 menunjukkan bahwa Religiusitas berpengaruh positif terhadap Ethnosentrisme Konsumen dengan nilai sebesar 0,347 sehingga semakin tinggi Religiusitas individu maka semakin tinggi pula Ethnosentrisme Konsumen. Tingkat signifikan Religiusitas terhadap Ethnosentrisme Konsumen sebesar 8,223 yang menunjukkan bahwa Religiusitas signifikan terhadap Ethnosentrisme Konsumen karena nilai t-statictics lebih besar dari nilai $t$-table $5 \%$ = 1,96). Probabilitas kesahalan ditunjukkan melalui hasil p-values yaitu sebesar 0,000 yang artinya peluang kesalahan dalam penelitian ini sangat kecil atau bahkan tidak ada karena nilai $p$-values lebih kecil dari alfa $(\alpha=5 \%)$. Dengan demikian dapat diambil kesimpulan bahwa hipotesis kedua dapat diterima. 
Hasil data yang terdapat pada Tabel 5 menunjukkan bahwa Skala Kecerdasan Budaya berpengaruh positif terhadap Ethnosentrisme Konsumen dengan nilai original sample sebesar 0,155 sehingga apabila semakin tinggi Skala Kecerdasan Budaya maka semakin tinggi pula Ethnosentrisme Konsumen. Data t-statictics menunjukkan tingkat signifikan sebesar 3,496, yang artinya Skala Kecerdasan Budaya signifikan terhadap Ethnosentrisme Konsumen karena nilainya lebih besar dari $t$-tabel $(5 \%=1,96)$.

Hasil penelitian menyimpulkan bahwa hipotesis pertama ditolak, hal ini dikarenakan hasil uji hipotesis pertama menunjukkan hasil yang berbeda dari penelitian Young, et.al.(2017). Individu yang cerdas akan budaya memiliki pengetahuan yang luas akan budaya lain juga budaya individu itu sendiri, sehingga menyadari adanya dampak baik dan buruk mengenai budaya baru yang masuk ke negaranya. Individu yang memiliki sifat Ethnosentris lebih memilih mengkonsumsi produk lokal daripada produk asing karena individu tersebut berpikir bahwa mengkonsumsi produk asing akan membahayakan perekonomian negara. Kecerdasan Budaya yang dimiliki individu mendorong individu untuk memahami dan menerapkan pengetahuan yang dimiliki mengenai budaya lain termasuk dalam mengkonsumsi.

Hasil analisis Religiusitas berpengaruh positif terhadap Skala Kecerdasan Budaya dengan nilai sebesar 0,51 sehingga semakin tinggi Religiusitas maka semakin tinggi pula Skala Kecerdasan Budaya, t-statictics sebesar 15,887 lebih besar dari $t$-tabel $(5 \%=1,96)$ menunjukkan bahwa Religiusitas berpengaruh siginifikan terhadap Skala Kecerdasan Budaya, sedangkan probabilitas kesalahan sangat kecil yaitu sebesar $0,000<$ alfa 5\%.Dari hasil penelitian tersebut maka dapat disimpulkan bahwa hipotesis ketiga diterima.

\section{SIMPULAN DAN SARAN}

Terdapat pengaruh positif antara Religiusitas dan Ethnosentrisme Konsumen. Hal ini sesuai dengan pernyataan Deb \& Sinha (2015) bahwa agama mempengaruhi kehidupan, kesejahteraan dan perilaku individu secara penuh.

Terdapat hubungan positif antara Skala Kecerdasan Budaya dan Ethnosentrisme Konsumen. Hal tersebut bertentangan dengan pernyataan dari Young, et.al. (2017) yang menyatakan bahwa Kecerdasan Budaya berpengaruh negatif terhadap Ethnosentrisme karena sikap Ethnosentrisme setiap individu sulit berubah dalam jangka waktu yang singkat. Namun, melalui hasil uji data yang telah dilakukan oleh peneliti menunjukkan bahwa terdapat pengaruh positif antara Skala Kecerdasan Budaya terhadap EthnosentrismeKonsumen

Terdapat hasil yang positif antara Religiusitas dan Skala Kecerdasan Budaya. Hal ini sesuai dengan temuan Beyers (2017) yang menyatakan bahwa agama dan budaya merupakan dua hal yang tidak dapat di pisahkan. Individu yang mempelajari agama tidak lepas dari mempelajari budaya begitu pula sebaliknya, individu yang mempelajari budayatidak lepas dari mempelajari agama. Melalui pernyataan ini maka dapat disimpulkan bahwa Religiusitas individu yang tinggi akan diikuti dengan tingginya Kecerdasan Budaya. 


\section{DAFTAR PUSTAKA}

Arikunto, S. (2013). Prosedur Penelitian: Suatu Pendekatan Praktik. Jakarta: Rineka Cipta.

Ang, S., \& Van Dyne, L. (2015). Handbook of Cultural Intelligence. London, UK: Routledge

Allport, G. W., \& Ross, J. M. (1967). Personal Religious Orientation and Prejudice. Journal of Personality and Social Psychology, 432-443.

Beyers, J. (2017). Religion and Culture: Revisting a Close Relative. HTS Teologiese Studies, 73 (1).

Deb, M., \& Sinha, G. (2015). Impact of Culture on Religiosity, Cosmopolitanism and Ethnocentrism. Asia Pacific. Journal of Marketing and Logistics.

Hair, Black, Babin, \& Anderson. (2010). Multivariate Data Analysis. 7th. New Jersey: Prentice Hall.

Janeba, E. (2004). International trade and cultural identity, NBER Working Paper, No 10426.

Pratono, A.H. (2019). Linking religiosity to citizenship behaviour under materialism attitude, International Journal of Ethics and Systems, 35(1), 75-89

Pratono, A.H. \& Arli, D. (2020). Linking global consumer culture and ethnocentric consumerism to global citizenship: exploring the mediating effect of cultural intelligence, International Journal of Sociology and Social Policy, 40(7/8), 659-675.

Sangadji, Mamang, E., \& Sopiah. (2010). Metodologi Penelitian-Pendekatan Praktis dalam Penelitian. Yogyakarta: ANDI

Shimp, T. A., \& Sharma, S. (1987). Consumer Ethnocentrism: Construction and Validation of the CETSCALE. Journal of Marketing Research 23, 280-9.

Sugiyono. (2015). Metode Penelitian Kombinasi (Mix Methods). Bandung: Alfabeta.

Thomas, D. C., Liao, Y., Aycan, Z., Cerdin, J.-L., Pekerti, A. A., Ravlin, E. C., et al. (2015). Cultural Intelligence: A Theory-Based, Short Form Measure. Journal of International Business Studies, 1-20.

Watson, J. J., \& Wright, K. (2000). Consumer Ethnocentrism and Attitude Toward Domestic and Foreign Products. European Journal of Marketing, Vol. 34 Nos 9/10 , 1149.

Yoo, B., \& Donthu, N. (2005). Developing and Validating a Multidimensional Consumer Based Brand Equity Scale. Journal of Business Research, Vol. 52 No. 1, 1-14.

Young, C. A., Haffejee, B., \& Corsun, D. L. (2017). The Relationship Between Ethnocentrism and Cultural Intelligence. International Journal of Intercultural Relations, 31-41.

Zikmund, William, G., Raymond, M., Jr, \& Faye W, G. (2003). Integrating Marketing Strategy and Information Technology. In Customer Relationship Management (p. 298). USA: John Willey \& Sons. 